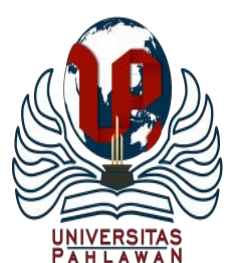

Jurnal Abdidas Volume 2 Nomor 5 Tahun 2021 Halaman 1086-1091 JURNAL ABDIDAS

http://abdidas.org/index.php/abdidas

\title{
Terapi Murrotal Dalam Penurunan Tekanan Darah Pada Lansia
}

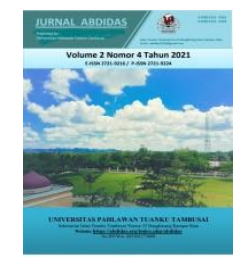

\author{
Revi Neini Ikbal ${ }^{1}$, Rebbi Permata Sari ${ }^{2} \bowtie$ \\ Keperawatan, STIKes Alifah Padang, Indonesia ${ }^{1,2}$ \\ E-mail : revineini@gmail.com ${ }^{1}$ Rebbi.permatasari@gmail.com ${ }^{2}$
}

\begin{abstract}
Abstrak
Terapi murotal (mendengarkan ayat-ayat suci Al-Qur'an) merupakan salah satu musik yang memiliki pengaruh positif bagi pendengarnya, termasuk penderita hipertensi. Dengan demikian maka perlunya dilakukan salah satu teknik relaksasi terapi murrotal dalam mengatasi penurunan tekanan darah pada penderita hipertensi. Pengabdian ini dilakukan di wilayah kerja Puskesmas Kuranji, Padang dengan sasaran penderita hipertensi di wilayah kerja Puskesmas Kuranji. Metode pelaksanaan yang akan dilakukan berupa survei epidemologi, penyuluhan kesehatan, demontrasi teknik relaksasi murrotal dan penyebaran leaflet. Setelah dilakukan kegiatan, peserta memperoleh informasi mengenai penyakit hipertensi dan praktek murotal untuk menurunkan hipertensi serta dapat mempraktekan terapi murotal secara mandiri.
\end{abstract}

Kata kunci : terapi murotal, hipertensi, pengabdian masyarakat

\section{Abstract}

Murotal therapy (listening to the holy verses of the Qur'an) is one of the music that has a positive influence on listeners, including people with hypertension. Thus, it is necessary to do one of the relaxation techniques of murrotal therapy in overcoming the decrease in blood pressure in patients with hypertension. This service is carried out in the working area of the Kuranji Health Center, Padang with the target of hypertension sufferers in the working area of the Kuranji Health Center. The implementation method will be in the form of an epidemiological survey, health education, demonstration of Murrotal Relaxation Techniques and leaflet distribution. After the activity, the public received information about hypertension and the practice of murotal to reduce hypertension. With this activity, people can do murotal therapy independently.

Keywords : murotal therapy, hypertension, community service

Copyright (c) 2021 Revi Neini Ikbal, Rebbi Permata Sari

$\triangle$ Corresponding author

Address : STIKes Alifah Padang

Email : Rebbi.permatasari@gmail.com

ISSN 2721- 9224 (Media Cetak)

DOI : https://doi.org/10.31004/abdidas.v2i5.436

ISSN 2721- 9216 (Media Online) 
1087 Terapi Murrotal Dalam Penurunan Tekanan Darah Pada Lansia - Revi Neini Ikbal, Rebbi Permata Sari

DOI: https://doi.org/10.31004/abdidas.v2i5.436

\section{PENDAHULUAN}

Hipertensi atau tekanan darah tinggi merupakan suatu keadaan medis dimana ditandai dengan meningkatnya kontraksi pembuluh darah arteri sehingga terjadilah resistensi aliran darah yang meningkatkan tekanan darah terhadap dinding pembuluh darah, kemudian meningkatkan kerja jantung agar bekerja lebih maksimal untuk memompa darah melalui pembuluh darah arteri yang sempit. Jika keadaan seperti ini terusmenerus berlangsung akan menyebabkan pembuluh darah dan jantung rusak (Prananda, 2017). Seseorang dinyatakan mengidap hipertensi bila tekanan darahnya $>140 / 90 \mathrm{mmHg}$ (Kemenkes RI, 2014).

Menurut WHO (2016), menunjukkan sekitar 1,13 miliar orang di dunia menderita hipertensi. Artinya, 1 dari 3 orang di dunia terdiagnosis menderita hipertensi. Setiap tahun, penyakit hipertensi atau tekanan darah tinggi menjadi salah satu penyebab kematian nomor satu didunia setelah stroke dan jantung dengan kematian hampir 9,4 juta orang pertahun. Tahun 2025 penderita hipertensi atau tekanan darah tinggi diperkirakan akan meningkat mencapai hampir 1,6 miliar orang. Selain itu hipertensi terbanyak terjadi pada usia lanjut yaitu pada usia 55-64 tahun sebanyak 45,9\%, usia 65-74 tahun sebanyak $57,6 \%$, dan usia $>76$ tahun sebanyak $63,8 \%$.

Data Global status Report On Noncommunicable Diasease menyebutkan $44 \%$ negara berkembang memiliki penderita hipertensi, sedangkan negara maju hanya $35 \%$ kawasan Afrika memegang posisi puncak penderita hipertensi sebanyak 46\%, kawasan Amerika menempati posisi $36 \%$, dan Asia Tenggara sebanyak 35\% (Candra, 2017). Indonesia berada dalam deretan 10 negara prevalensi hipertensi tertinggi didunia, bersama Myanmar, India, Srilanka, Bhutan, Thailand, Nepal, dan Maldives (Anonim,2013 dalam Putri, 2017).

Penderita hipertensi di Indonesia sebanyak $31,7 \%$ dan sebagian besar penderita hipertensi adalah lansia. Indonesia memiliki 34 provinsi dan salah satunya provinsi Sumatera Barat menempati posisi ke 20 dengan penderita hipertensi terbanyak dari provinsi yang ada di indonesia (Riskesdas,2018). Penderita hipertensi di Sumatera Barat juga lebih banyak terjadi pada lanjut usia. Penderita hipertensi pada usia 60 tahun keatas sekitar 650.000 orang $(19,1 \%)$ dari 4,4 juta jiwa penduduk, sedangkan penderita hipetensi yang berusia 60 tahun kebawah jumlahnya mencapai 450.000 orang $(17,45 \%)$ (Riskesdas, 2018).

Secara garis besar hipertensi dapat diatasi dengan cara farmakologi dan non farmakologi. Secara farmakologi adalah penatalakasanaan hipertensi dengan menggunakan obat-obatan. Penggunaan obat hipertensi modern seperti obatobatan golongan diuretik, betabloker, antagonis kalsium, dan penghambatan konpersi enzim angitensin (Junaeda, Yulianti, \& Rinata, 2013). Sedangkan pengobatan secara non farmakologi dapat dilakukan dengan mengubah gaya hidup yang lebih sehat, latihan fisik, terapi musik, terapi relaksasi progresif dan terapi alternatif komplementer seperti hidroterapi atau yang dikenal terapi rendam kaki menggunakan air hangat dan terapi murottal yang bisa dilakukan setiap saat (Harnani \& Axmalia, 2017). 
1088 Terapi Murrotal Dalam Penurunan Tekanan Darah Pada Lansia - Revi Neini Ikbal, Rebbi Permata Sari

DOI: https://doi.org/10.31004/abdidas.v2i5.436

Terapi murotal (mendengarkan ayat-ayat suci Al-Qur'an) merupakan salah satu musik yang memiliki pengaruh positif bagi pendengarnya. Terapi murotal dapat mengurangi tingkat kecemasan pasien dalam menjalani operasi (Handayani. dkk, 2014). Dalam konfrensi tahunan ke XVII IKATAN Dokter Amerika, dengan hasil peneltian bahwa dengan mendengarkan ayat suci Al- Qur'an memiliki pengaruh yang signifikan dalam menurunkan ketegangan urat syaraf (Remolda, 2015).

Hasil Penelitian lainya yang dilakukan oleh Revi dan Rebbi dengan judul Pengaruh Terapi Murotal Terhadap Penurunan Tekanan Darah Pada Pasien Hipertensi Di RS X Kota Padang Tahun 2018 diperoleh hasil ada pengaruh terapi murotal terhadap penurunan tekanan darah pada pasien hipertensi.

Berdasarkan uraian diatas dan hasil basis penelitian yang dilakukan peneliti sebelumnya bahwa dampak yg diperoleh dari hipertensi antara lain payah jantung, stroke, kerusakan ginjal dan kerusakan penglihatan. Dengan demikian maka perlunya dilakukan salah satu teknik relaksasi terapi murrotal dalam mengatasi penurunan tekanan darah pada penderita hipertensi.

\section{METODE}

Adapun tujuan dari pelaksanaan pengabdian kepada masayrakat ini adalah meningkatkan pengetahuan dan mendemostrasikan agar memahami tentang salah satu teknik relaksasi terappi murrotal dalam penurunan tekanan darah.

Metode pelaksanaan yang akan dilakukan dalam rangka kegiatan pengabdian kepada masayrakat tentang terapi murrotal dalam menurunkan tekanan darah dapat dijelaskan sebagai berikut :

1. Survei epidemologi

Pada kegiatan ini, pelaksana kegiatan melakukan survey ke puskesmas terkait kasus penyakit terbanyak di wilayah puskesmas kuranji. Data yang diperoleh kemudian ditelaah dan dimanfaatkan sebagai baseline data untuk kegiatan selanjutnya. Hasil dari survei tersebut diperoleh 5 kasus terbanyak pada wilayah kerja puskesmas kuranji salah satunya adalah penyakit hipertensi.

2. Penyuluhan Kesehatan

Kegiatan ini berupa ceramah dan focus group discution (FGD) tentang penyakit hipertensi dan teknik relaksasi terapi murrotal dalam menurunkan tekanan darah.

3. Demontrasi Teknik Relaksasi Murrotal

Kegiatan ini berupa menukur tekanan darah sebelum melaksanakan teknik relaksasi terapi murrotal dan memeriksa kembali tekanan darah setelah teknik relaksasi terapi murrotal dilakukan.

4. Penyebaran Leaflet

Leaflet disebarkan setelah penyuluhan selesai sebagai bacaan peserta di rumah sehingga peserta dapat merepkan teknik relaksasi terapi murrotal secara mandiri.

Pelaksanaan Kegiatan

1. Topik : Teknik Relaksasi Terapi Murrotal Dalam Menurunkan Tekanan Darah

2. Sasaran : Penderita Penyakit Hipertensi Di Wilayah Kerja Puskesmas Kuranji 
1089 Terapi Murrotal Dalam Penurunan Tekanan Darah Pada Lansia - Revi Neini Ikbal, Rebbi Permata Sari

DOI: https://doi.org/10.31004/abdidas.v2i5.436

3. Metode : Ceramah, Tanya jawab

4. Media dan alat : Laptop dan power point

5. Waktu dan tempat

a. Hari/ Tanggal : Minggu/14 Februari 2021

b. Pukul : $09.00 \mathrm{WIB}$ s/d Selesai

c. Tempat : Wilayah Kerja

Puskesmas Kuranji

6. Pengorganisasian

a. Moderator : Ns. Rebbi Permata Sari, M.Kep

b. Penyaji : Ns. Revi Neini Ikbal, M.Kep

c. Fasilitator : Rahmatika

d. Obsever : Yona Oktiana, weni Shelomita, Anggun Marsa

e. Dokumentasi : Lusy Oktaviana

\section{HASIL DAN PEMBAHASAN}

Kegiatan dilakukan sesuai dengan jadwal yang sudah direncanakan. Kegiatan dimulai dengan pembukaan acara kegiatan serta penyampaian/penjelasan singkat mengenai tujuan kegiatan serta cakupan materi yang akan diberikan.

Adapun topik yang berikan kepada masyarakat yaitu pembahasan mengenai penyakit hipertensi mencakup penyebab, etiologi, gejala dan cara pencegahan penyakit hipertensi. Selain itu juga di jelaskan mengenai terapi murotal sebagai cara menurunkan hipertensi/tekanan darah pada lansia.
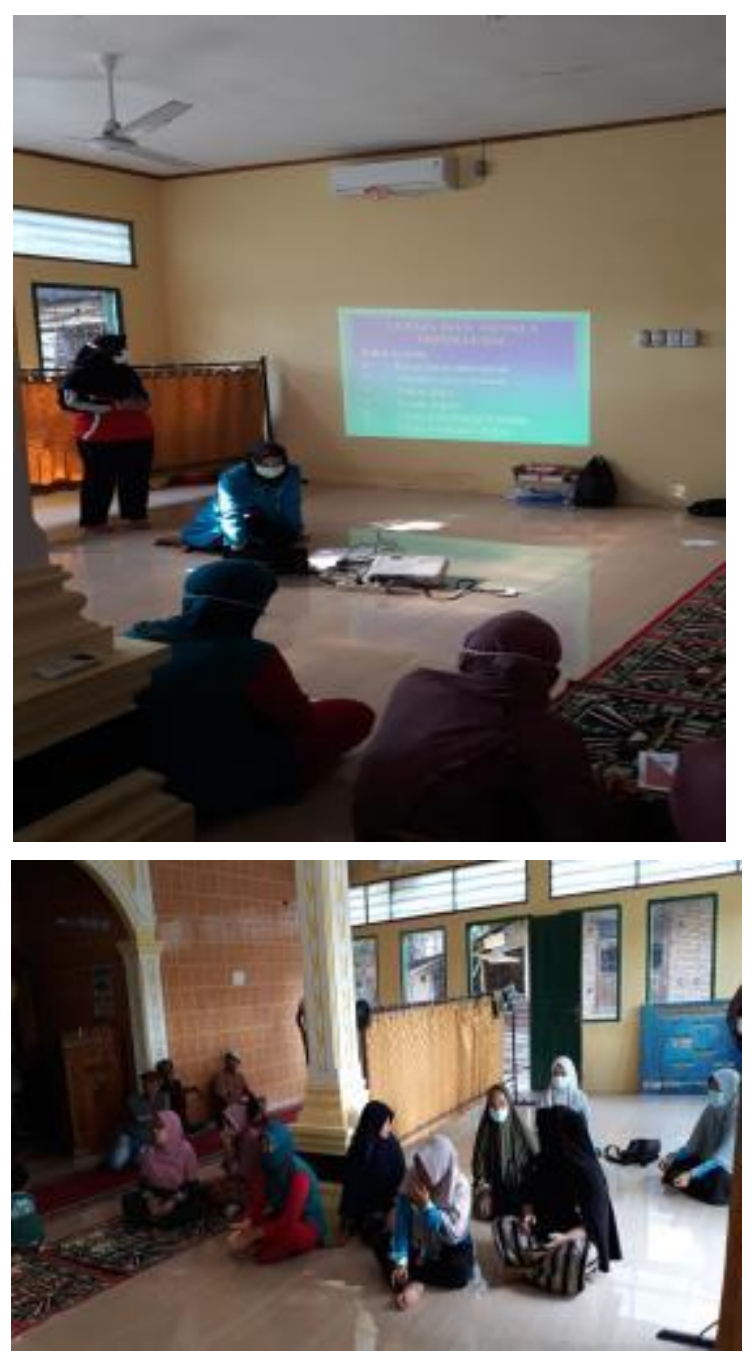

Gambar 1. Kegiatan Penyuluhan

Selama kegiatan penyuluhan, peserta mendengarkan dengan seksama dan peserta antusias bertanya serta penyaji menjawab pertanyaan dari peserta. Selanjutnya tim pengabdi juga memberikan terapi murotal kepada peserta dengan menghidupkan murotal ayat suci Al-quran selama 10 menit lalu dengan tekanan darah diukur sebelum dan setelah peserta mendengarkan murotal Al-quran. 
1090 Terapi Murrotal Dalam Penurunan Tekanan Darah Pada Lansia - Revi Neini Ikbal, Rebbi Permata Sari

DOI: https://doi.org/10.31004/abdidas.v2i5.436

Tabel 1. Susunan Acara Kegiatan Penyuluhan

\begin{tabular}{|c|c|c|}
\hline No & Tahap & Kegaiatan Penyuluhan \\
\hline \multirow[t]{2}{*}{1} & Pembukaan & $\begin{array}{ll}\text { 1. } & \text { Memberi salam } \\
\text { 2. } & \text { Memperkenalkan diri } \\
\text { 3. } & \text { Menjelaskan cakupan materi } \\
\text { 4. } & \text { Melakukan kontrak waktu } \\
\end{array}$ \\
\hline & $\begin{array}{l}\text { Penyajian } \\
\text { Maten }\end{array}$ & $\begin{array}{ll}\text { 1. } & \text { Menggali pengetahuan peserta tentang penyakit hipertensi } \\
\text { 2. } & \text { Memberikan reinforcement positif atas jawaban peserta } \\
\text { 3. } & \text { Menjelaskan kepada peserta tentang pengertian penyakit hipertensi } \\
\text { 4. } & \text { Menggali pengetahuan peserta tentang penyebab penyakithipertesni } \\
\text { 5. } & \text { Memberikan reinforcement positif atas jawaban peserta } \\
\text { 6. } & \text { Menjelaskan kepada peserta tentang etiologi penyakit hipertensi } \\
\text { 7. } & \text { Menggali pengetahuan peserta tentang tanda gejala hipertensi } \\
\text { 8. } & \text { Memberikan reinforcement positif atas jawaban peserta } \\
\text { 9. } & \text { Menjelaskan kepada peserta tentang tanda gejala penyakit hipertensi } \\
\text { 10. Menggali pengetahuan peserta tentang cara pencegahan penyakit hipertensi } \\
\text { 11. Memberikan reinforcement positif atas jawaban peserta } \\
\text { 12. Menjelaskan kepada peserta tentang cara pencegahan penyakit hipertensi } \\
\text { 13. Menggali pengetahuan peserta tentang penatalaksanan penyakit hipertensi } \\
\text { 14. Memberikan reinforcement positif atas jawaban peserta } \\
\text { 15. Menjelaskan kepada peserta tentang penatalaksanaan penyakit hipertensi } \\
\text { 16. Menggali pengetahuan peserta tentang teknik relaksasi terapi murrotal } \\
\text { 17. Memberikan reinforcement positif atas jawaban peserta } \\
\text { 18. Menjelaskan kepada peserta tentang teknik relaksasi murrotal } \\
\text { 19. Medemonstrasikan teknik relaksasi murrotal } \\
\text { 20. Melakukan pemeriksaan tekanan darah sebelum dilakukan teknik relaksasi murrotal } \\
\text { 21. Melaksanakan teknik relaksasi murrotal dengan memutar video ayat al-qur'an } \\
\text { 22. Melakukan pemeriksaan tekanan darah setelahdilakukan teknik relaksasi murrotal }\end{array}$ \\
\hline & Diskusi & Peserta mengajukan pertanyaan dan dijawab oleh narasumber/penyaji materi \\
\hline & Penutup & $\begin{array}{l}\text { 1. Menyimpulkan materi penyuluhan } \\
\text { 2. Menutup penyuluhan dan memberi salam }\end{array}$ \\
\hline
\end{tabular}
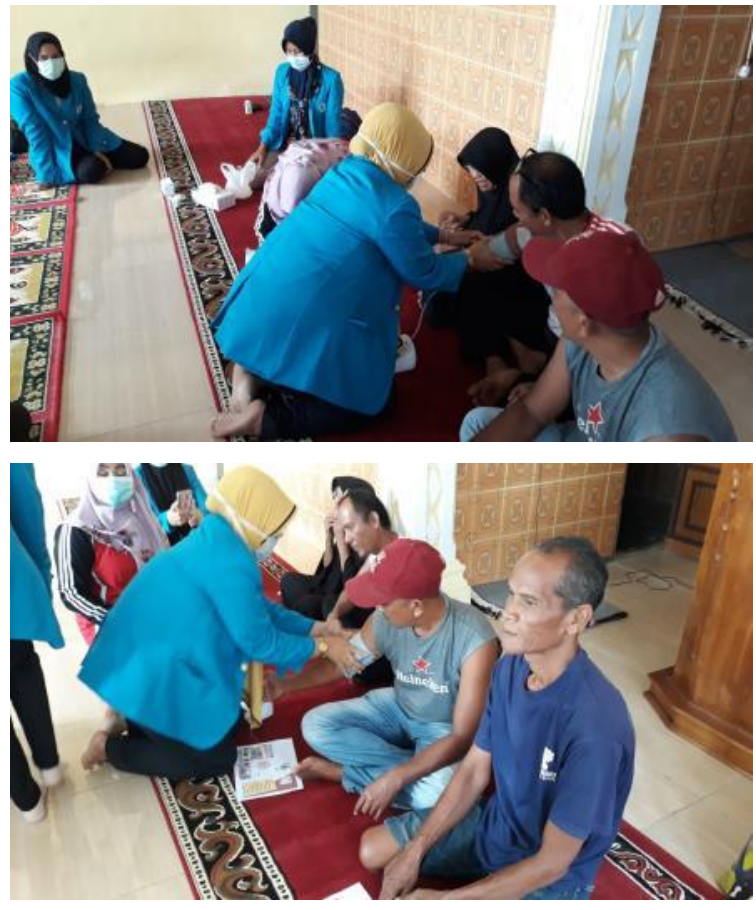

Gambar 2. Pengukuran Tekanan Darah Peserta Kegiatan
Setelah terapi murotal dilakukan, tekanan darah diukur kembali oleh tim pengabdian. Setelah pengukuran di dapatkan terjadinya penurunan tekanan darah peserta setelah melakukan terapi murotal. Secara keseluruhan kegiatan terlaksana sesuai dengan waktu yang direncankan dan seluruh peserta dapat mengikuti kegiatan penyuluhan dan berperan aktif dalam kegiatan.

Setelah dilakukannya kegiatan penyuluhan Terapi Murrotal Dalam Penurunan Tekanan Darah ini, pengetahuan peserta bertambah mengenai hipertensi sehingga dapat menghindari faktor penyebab dan mengenali gejala-gejala hipertensi. Selain itu, terapi murotal sebagai upaya menurunkan tekanan darah juga bisa dilaksanakan secara mandiri oleh peserta. 
1091 Terapi Murrotal Dalam Penurunan Tekanan Darah Pada Lansia - Revi Neini Ikbal, Rebbi Permata Sari

DOI: https://doi.org/10.31004/abdidas.v2i5.436

\section{DAFTAR PUSTAKA}

Annisa, T. (2017). Pengaruh Mendengarkan dan Membaca Al-Quran Terhadap Penurunan Tekanan Darah Pada Lansia Hipertensi Di Panti Sosial Tresna Werdha Mabaji Gowa. UIN Alauddin Makassar. (Jurnal)

Ardiansyah, M. (2012). Medikal Bedah Untuk Mahasiswa. Yogyakarta: Diva Press. Dipiro, J.T., Dipiro,C.V., Wells, B.G., dan Schwinghammer, T.L. 2015.

Pharmacotherapy Handbook. 9th edition. McGrawHill. United States

Fratidhina, Y. (2016). Pengaruh Mendengarkan Murottal Terhadap Penurunan Tekanan Darah Pada Ibu Hamil Preeklamsi Di Rsia Pku Muhammadiyah Tangerang, 1(2), 4047

Gale J, Wells AP, Wilson G. Effects of exercise on ocular physiology and disease.Surv Ophthalmol [Internet]. Elsevier; 2009 Jan 5 [cited 2015 Nov19];54(3):349-55. Available from:http://www.surveyophthalmol.com/art icle/S003962570900040X/fulltext

Christanto,et al., (2014), Kapita Selekta Kedokteran. Ed IV. Jakarta: Media Aeskulapius.

Elizabeth J. Corwin, (2011) Asuhan Keperawatan Kardiovaskuler Edisi V Jakarta

Handayani, R., Fajarsari, D., Asih, D.R.T., \& Rohmah, D.N. (2014). Pengaruh Terapi Murottal Al-Quran untuk Penurunan Nyeri Persalinan dan Kecemasan pada Ibu Bersalin Kala I Fase Aktif. Jurnal Ilmiah Kebidanan. 5(2), 1-15.

Hasdianah, \& Suprapto, S. I. (2016). Patologi \& Patofisiologi Penyakit. Yogyakarta: Nuha Medika.

Kemenkes RI. (2015). Infodatin Hipertensi. Pusat Data Dan Informasi. (Jurnal) Nuraini, B. 2015. Risk Fators of Hypertension. Faculty of Medicine, University of Lampung. vol. 4, No. 5, pp. 11
PERKI (2015), Pedoman Tatalaksana Hipertensi Pada Penyakit Kardiovskuler. Edisi Pertama

Isnawati. (2017). Efektivitas terapi murottal alqur'an dan terapi musik terhadap tingkat kecemasan mahasiswa keperawatan semseter viii uin alauddin makassar. UIN Alauddin Makassar.

Sutters, M., (2017). Systemic hypertension, in McPhee, S., Papadakis, M.A.(eds).

Current Medical Diagnosis and Treatment. McGrawHill Lange. New York. P: 439-71

Turana, Y., and Juanda, G.N., (2017). Tatalaksana hipertensi: modifikasi gaya hidup in: Taruna, Y. and Widyantoro, B. Buku Ajar Hipertensi. Perhimpunan Dokter Hipertensi Indonesia.Jakarta 